\title{
On Bond-slip of EB-FRP/Concrete Interface in Shear Under Fatigue Loading: Review and Synthesis of Experimental Studies and Models
}

\author{
Abbas Fathi, Georges El-Saikaly*, Omar Chaallal \\ Dept. of Construction Engineering, École de Technologie Supérieure (ÉTS), University of Quebec, Montreal \\ (QC), H3C 1K3, Canada \\ E-mail: Abbas.fathi.1@ens.etsmtl.ca; Georges.el-saikaly@etsmtl.ca (Corresponding author); \\ Omar.Chaallal@etsmtl.ca
}

Received: 16 June 2021; Accepted: 29 September 2021; Available online: 20 November 2021

\begin{abstract}
Reinforced concrete (RC) structures subjected to cyclic fatigue loading are prone to progressive damage. Among the types of structural damage, those leading to shear deficiencies can result in sudden rupture of structures without warning. Hence, RC structures deficient in shear urgently need retrofitting. The use of externally bonded (EB) fiber-reinforced polymer (FRP) composites presents many advantages and is a very promising technology for shear strengthening of RC structures. This paper encompasses a wide range of research findings related to the interaction between concrete and FRP under fatigue loading. The behavior of the bond between FRP and concrete plays a major role in the failure mode of FRP shear-strengthened structures especially under fatigue. Therefore, it is of interest to characterize the FRP/concrete interaction using appropriate models with respect to the influencing parameters. The paper will first discuss existing design guidelines and considerations related to the fatigue behavior of RC structures. A thorough review of available literature on EB-FRP/concrete bond in shear under cyclic fatigue loading will then be presented, with a focus on proposed bond-slip models and finite element studies of the FRP/concrete interface under fatigue loading.

Keywords: Fatigue loading; Bond-slip models; Shear; Reinforced concrete structures; Fiber-reinforced polymer (FRP); FRP/concrete interface; Finite element analysis (FEA).
\end{abstract}

\section{Introduction}

Many reinforced concrete (RC) structures such as bridge girders are expected to resist high numbers of cycles of fatigue loading, mainly due to traffic loads, during their life span. Many existing bridge structures in Canada and worldwide were designed according to old design codes in which the design loads did not consider the increased service loads caused by higher present-day traffic volume [1, 2]. Indeed, out of over 8,000 bridges reported on by the Canadian National Highway System, $60 \%$ are more than 30 years old, about $4 \%$ are rated as being in poor condition, and $80 \%$ need some sort of retrofitting [3]. In the United States, reports also show that out of 615,002 bridges, about $9 \%$ are classified as structurally deficient [4]. A large proportion of RC bridge structures show considerable signs of damage due to concrete deterioration, corrosion of steel reinforcement, and lack of sufficient load-carrying capacity according to current design guidelines [1]. Therefore, rehabilitation of such structures to withstand cyclic fatigue loads has always been a major concern for engineers. Shear failure, which is a common failure mode that can be caused by fatigue loading, often occurs suddenly and without warning. This mode of failure is characterized by diagonal tension cracks that are mainly due to the combined effects of flexural (bending) and shearing action. The use of externally bonded (EB) fiber-reinforced polymer (FRP) composites to strengthen deficient RC beams is widely accepted. EB-FRP composites present many advantages such as high strength-to-weight ratio, corrosion resistance, fatigue resistance, light weight, and ease of application [5-7].

The fatigue life (fatigue strength) of an EB-FRP strengthened RC structure is defined as the number of load cycles leading up to the structural failure. Indeed, the stress level in the steel reinforcement is known as the main component that determines the fatigue life of RC structures EB-FRP strengthened, particularly in flexure. Therefore, the fatigue life of a structure is generally represented by an S-N curve, which is in terms of stress versus the logarithm of the number of load cycles. Experimental investigations have revealed that the fatigue life of FRP strengthened RC structures depend on their failure modes. The most common failure modes that have been observed in EB-FRP shear-strengthened RC structures under fatigue loading include crushing of concrete struts, debonding of FRP from concrete, yielding and fracture of longitudinal tensile steel bars, and steel stirrup rupture $[1,8]$. However, it is widely accepted that the fatigue life of FRP strengthened RC beams in flexure is typically 
governed by the fatigue strength of the internal steel reinforcement. Indeed, it is reported that fracture of the steel reinforcement is the dominant failure mode in such structures [7]. As far as the fatigue strength of steel goes, a downward trend appears in the S-N curve until a stress level, known as the endurance limit, beyond which the curve progresses horizontally along the $\mathrm{N}$-axis. Therefore, steel tends to resist an indefinite number of load cycles at its endurance limit. For concrete, however, the curve seems to drop to its fatigue strength, as shown in Fig. 1 [7]. More specifically, no endurance limit has been observed in the fatigue life of concrete under ten million cycles of fatigue load, but its fatigue strength in compression, tension, or flexure under the same number of load cycles has been found to be approximately $55 \%$ of its static strength. This level of residual strength is in fact the ultimate load reached by the specimens under quasi-static loading condition after they experienced 10 million cycles [9]. As for the fatigue performance of FRP composites, carbon FRP (CFRP) has been found to have the longest fatigue life among FRP materials [10]. Moreover, a typical CFRP composite can exhibit an endurance limit of $60 \%$ to $70 \%$ of its initial static ultimate strength [11].

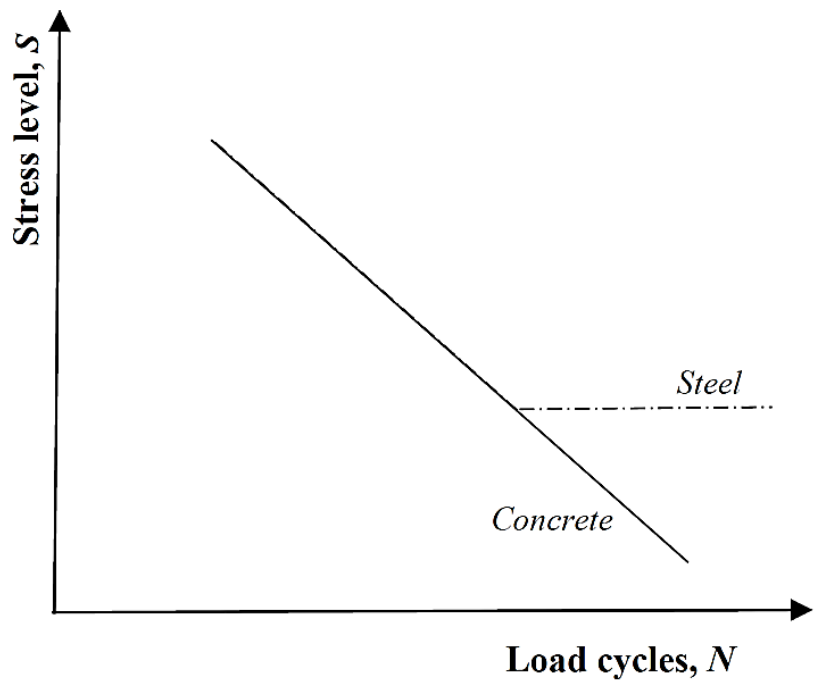

Fig. 1. Schematic S-N curves of concrete and steel

Through extensive research investigations on the fatigue behavior of RC beams strengthened in flexure with EB-FRP, researchers have developed numerous S-N models to determine the fatigue failure of internal longitudinal tensile reinforcement, which has been known to be the governing factor in the fatigue life of EB-FRP strengthened RC beams in flexure [12-17].

Considering the performance of an EB-FRP shear-strengthened RC beam under fatigue loading, the FRP/concrete bond behavior can have a significant effect on the fatigue strength of the structure because premature debonding at the interface prevents the EB-FRP from attaining its full capacity. Hence, it is of great interest to evaluate the fatigue life of RC structures strengthened in shear with EB-FRP in terms of the behavior of the $\mathrm{FRP} /$ concrete bond and to investigate the influencing parameters affecting the interlaminar interaction between FRP and concrete.

Despite considerable research on shear strengthening of RC beams using EB-FRP systems under monotonic loading, the fatigue behavior of EB-FRP shear-strengthened RC structures has not been fully documented. Kim and Heffernan [5] presented the state of the art on the fatigue performance of FRP-strengthened RC structures in flexure. Various fatigue-related parameters were investigated, including applied load range, FRP bond behavior, crack propagation, environmental effects, and failure modes. Another state-of-the-art review was published by Oudah and El-Hacha [7], in which a parametric study was carried out on the fatigue behavior of RC structures strengthened in flexure with FRP composites. Furthermore, a few other literature reviews have been published on the fatigue behavior of FRP-strengthened RC beams $[10,18,19]$. It is noteworthy that these studies focused on the flexural performance of RC structures strengthened with EB-FRP under cyclic fatigue loading. In contrast, investigations related to shear behavior were not considered in previous literature reviews.

Prior investigations on the fatigue behavior of concrete/FRP bond have demonstrated the reliance of the resistance of FRP strengthened concrete structures on the bond failure mechanism, thereby making it necessary to determine the bond-slip model of concrete/FRP interface in such structures [20,21]. An accurate bond-slip model needs to take into account all the influencing parameters including concrete strength, FRP bonded length, FRP-toconcrete width ratio, and fatigue loading amplitude. A review of related literature shows that a bond-slip model with the ability to consider all the aforementioned factors under fatigue conditions has yet to be developed. The aim of this paper is to introduce all the proposed models related to the bond behavior at FRP/concrete interface 
and identify the pros and cons of each of them. Furthermore, the application of bond-slip models in finite element modeling (FEM) of FRP/concrete interface is evaluated through reported numerical studies. Based on the existing gaps identified herein, further investigations could be conducted on the FRP/concrete bond behavior under fatigue loading.

The state of our knowledge is presented in the following sections to shed light on the fatigue behavior of EBFRP shear-strengthened RC structures by examining bond behavior. To that end, this paper is organized into several sections covering a wide range of aspects, which include: i) a review of existing design codes related to the fatigue life of concrete as well as FRP composites; ii) research findings regarding the fatigue behavior of the bond at the FRP/concrete interface; and iii) a review of finite-element simulations of the FRP/concrete bond under fatigue loading. Finally, the gaps and shortcomings in the available published research are identified, along with recommendations for further investigation.

\section{Design code provisions}

The fatigue stress limits of concrete and FRP materials are specified in many design code provisions. The stress in FRP should not exceed the maximum applied stress, including sustained and cyclic loading. For example, the maximum stress specified by ACI-440.2R [11] is equal to $20 \%, 30 \%$, and $55 \%$ of ultimate FRP strength for glass FRP (GFRP), aramid FRP (AFRP), and CFRP, respectively, whereas these stress limits are 25\%, 35\%, and 65\% according to CSA-S6 [22].

For RC structures under flexural fatigue loading, ACI-215R [9] limits the stress range of concrete to $40 \%$ of its compressive strength, whereas according to ACI-440.2R [11], the compressive stress in concrete should be limited to $60 \%$ of its strength for RC structures strengthened with EB-FRP under cyclic service load.

On the basis of experimental observations, an EB-FRP strengthened RC member is exposed to fatigue damage when the cyclic load range is over $60 \%$ of its monotonic yield capacity [23]. Furthermore, in EB-FRP strengthened $\mathrm{RC}$ structures, the bond strength at the FRP/concrete interface is greatly affected by the tensile strength of the concrete substrate. The concrete substrate is the weakest link in the FRP/concrete interface, and its tensile strength and soundness govern the effectiveness of externally bonded FRP systems [11]. Therefore, it is recommended that the minimum required tensile strength of concrete in EB-FRP applications be greater than $1.5 \mathrm{MPa}[11,22,23]$.

\section{Fatigue behavior of FRP/concrete interface under cyclic loading}

The FRP/concrete interface plays a major role in the shear performance of EB-FRP strengthened RC structures under fatigue loading. The FRP/concrete bond can be affected by numerous parameters including concrete strength, FRP bonded length, FRP-to-concrete width ratio and fatigue loading amplitude. An investigation by Ko and Sato [24] on the bond behavior of different FRP materials including carbon, aramid, and polyacetal revealed that concrete specimens bonded with carbon FRP (CFRP) materials featured superior performance in terms of load-carrying capacity and initial stiffness compared to those strengthened with aramid and polyacetal FRPs. Increasing FRP stiffness by using multiple layers was also reported to increase the maximum bond strength [24]. In addition, the FRP/concrete bond is likely to undergo fatigue failure when the adhesive is exposed to temperatures higher than its glass transition temperature or as a result of freezing and thawing [10]. Furthermore, exposure to a hygrothermal environment (high temperature and moisture) can shorten the fatigue life of the CFRPconcrete interface and result in aggressive decay of the bond behavior [25]. Since the fatigue failure mode of RC structures shear-strengthened with EB-FRP depends on the FRP/concrete interaction, research has been carried out to develop bond-slip models for the FRP/concrete interface under cyclic loading considering various influencing factors such as concrete strength, FRP-to-concrete width ratio, fatigue loading amplitude, and bond length. Table 1 presents details of experimental investigations that were conducted to evaluate the behavior of bond between EB-FRP and concrete under fatigue loading. In the following sections, the proposed bond-slip models as well as the fatigue life models of FRP-to-concrete interface are presented. In addition, the influencing parameters of the bond between EB-FRP and concrete in fatigue loading conditions are thoroughly discussed.

\subsection{Bond-slip models of FRP/concrete interface}

A number of bond-slip models have been proposed to characterize the interfacial behavior of FRP/concrete bond under static loading. Table 2 lists the proposed local bond slip models under static loading reported in the literature. Fig. 2 shows the developed bond-slip curves for an FRP bonded concrete specimen under static loading with the following properties: $f_{c}^{\prime}=30 \mathrm{MPa}, f_{t}=2.9 \mathrm{MPa}, b_{f}=75 \mathrm{~mm}, b_{c}=150 \mathrm{~mm}, t_{f}=0.13 \mathrm{~mm}, E_{f}=230 \mathrm{GPa}$, $E_{c}=32.5 \mathrm{GPa}$. The aforementioned symbols are defined in Table 2. 
Table 1. Details of experimental investigations on the fatigue behavior of FRP/concrete bond along with the investigated parameters.

\begin{tabular}{|c|c|c|c|c|c|c|c|c|c|c|c|c|c|c|}
\hline \multirow[b]{2}{*}{ Authors } & \multirow{2}{*}{ 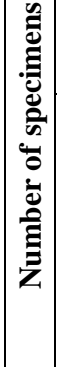 } & \multicolumn{2}{|c|}{ Test specifications } & \multicolumn{4}{|c|}{ Fatigue loading condition } & \multicolumn{7}{|c|}{ Influencing parameters } \\
\hline & & $\begin{array}{l}\text { Pull-out } \\
\text { Test set-up }\end{array}$ & $\begin{array}{c}\text { FRP } \\
\text { system }\end{array}$ & 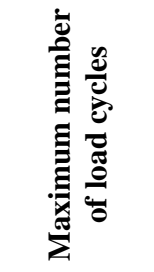 & 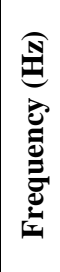 & 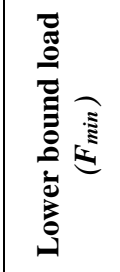 & 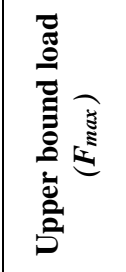 & 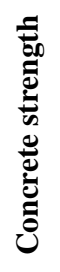 & 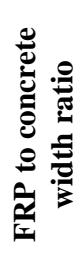 & 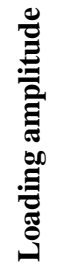 & 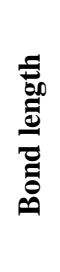 & 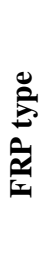 & 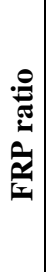 & 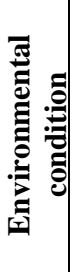 \\
\hline $\begin{array}{l}\text { Bizindavyi et } \\
\text { al. [26] }\end{array}$ & 46 & $\begin{array}{l}\text { Single lap } \\
\text { shear }\end{array}$ & $\begin{array}{c}\text { FRP } \\
\text { laminates }\end{array}$ & - & 1 & var & var & & $\checkmark$ & $\checkmark$ & $\checkmark$ & $\checkmark$ & & \\
\hline $\begin{array}{c}\text { Ko and Sato } \\
\text { [24] }\end{array}$ & 54 & $\begin{array}{c}\text { Double lap } \\
\text { shear }\end{array}$ & $\begin{array}{l}\text { CFRP } \\
\text { sheets }\end{array}$ & - & - & - & - & & & & & $\checkmark$ & $\checkmark$ & \\
\hline $\begin{array}{l}\text { Diab et al. } \\
\text { [27] }\end{array}$ & 17 & $\begin{array}{c}\text { Double lap } \\
\text { shear }\end{array}$ & $\begin{array}{l}\text { CFRP } \\
\text { sheets }\end{array}$ & 3 million & 5 & $10 \% \mathrm{f}_{\text {u.b }}$ & $\begin{array}{c}30-80 \% \\
f_{u . b}\end{array}$ & & & $\checkmark$ & & & & \\
\hline $\begin{array}{c}\text { Carloni et al. } \\
\text { [28] }\end{array}$ & 7 & $\begin{array}{c}\text { Single lap } \\
\text { shear }\end{array}$ & $\begin{array}{l}\text { CFRP } \\
\text { sheets }\end{array}$ & - & 1 & var & var & & & $\checkmark$ & & & & \\
\hline Li et al. [29] & 21 & $\begin{array}{c}\text { Four point } \\
\text { bending }\end{array}$ & $\begin{array}{l}\text { CFRP } \\
\text { sheets }\end{array}$ & 2 million & 2.5 & $15 \% \mathrm{f}_{\text {u.b }}$ & $\begin{array}{c}45-80 \% \\
f_{u . b}\end{array}$ & $\checkmark$ & $\checkmark$ & $\checkmark$ & $\checkmark$ & & & \\
\hline $\begin{array}{l}\text { Zheng et al. } \\
\text { [25] }\end{array}$ & 17 & $\begin{array}{c}\text { Double lap } \\
\text { shear }\end{array}$ & $\begin{array}{l}\text { CFRP } \\
\text { laminates }\end{array}$ & - & 10 & var & var & & & $\checkmark$ & & & & $\checkmark$ \\
\hline Zhu et al. [30] & 9 & $\begin{array}{l}\text { Four point } \\
\text { bending }\end{array}$ & $\begin{array}{l}\text { CFRP } \\
\text { sheets }\end{array}$ & 2.5 million & 2.5 & $15 \% \mathrm{f}_{u . b}$ & var & $\checkmark$ & & $\checkmark$ & & & & \\
\hline Li et al. [31] & 15 & $\begin{array}{c}\text { Four point } \\
\text { bending }\end{array}$ & $\begin{array}{l}\text { CFRP } \\
\text { sheets }\end{array}$ & - & 2.5 & $15 \% \mathrm{f}_{\text {u.b }}$ & var & $\checkmark$ & $\checkmark$ & $\checkmark$ & $\checkmark$ & & & \\
\hline Zhang [32] & 15 & $\begin{array}{l}\text { Double lap } \\
\text { shear }\end{array}$ & $\begin{array}{c}\text { CFRP } \\
\text { laminates }\end{array}$ & $\begin{array}{c}1 \\
\text { million }\end{array}$ & 1 & $10 \% \mathrm{f}_{\text {u.b }}$ & \begin{tabular}{|r|}
$50-$ \\
$90 \% \mathrm{f}_{u . b}$
\end{tabular} & & & $\checkmark$ & & & & \\
\hline Xie et al. [33] & 26 & $\begin{array}{c}\text { Four point } \\
\text { bending }\end{array}$ & $\begin{array}{l}\text { BFRP } \\
\text { sheets }\end{array}$ & $\begin{array}{c}2 \\
\text { million }\end{array}$ & 10 & var & var & & & $\checkmark$ & & & & $\checkmark$ \\
\hline
\end{tabular}

* Note: f_(u.b)= Static bond capacity

Table 2. Available bond-slip models under static loading.

\begin{tabular}{|c|c|}
\hline Authors & Bond-slip models \\
\hline $\begin{array}{l}\text { Neubauer and Rostasy } \\
\text { [34] }\end{array}$ & $\begin{array}{c}\tau= \begin{cases}\tau_{\max }\left(\frac{s}{s_{0}}\right) & s \leq s_{0} \\
0 & s>s_{0}\end{cases} \\
\tau_{\max }=1.8 k_{b} f_{t} \quad, \quad s_{0}=0.202 k_{b} \quad, \quad \beta_{w}=\sqrt{1.25 \times \frac{2-b_{f} / b_{c}}{1+b_{f} / 400}}\end{array}$ \\
\hline De Lorenzis et al. [35] & $\begin{array}{c}\tau=K_{\text {int }} \times s \\
K_{\text {int }}=G_{\text {int }} / t_{\text {int }} \quad, \quad \tau_{\text {max }}=0.0182\left(n_{f} t_{f} E_{f}\right)^{0.5}, \quad\left(n_{f} t_{f} E_{f} \text { in } M P a, m m\right)\end{array}$ \\
\hline Nakaba et al. [36] & $\begin{array}{c}\tau=\tau_{\max }\left(\frac{S}{s_{0}}\right)\left[3 /\left(2+\left(\frac{S}{s_{0}}\right)^{3}\right)\right] \\
\tau_{\max }=3.5 f_{c}^{\prime 0.19}, \quad s_{0}=0.065\end{array}$ \\
\hline Monti et al. [37] & $\begin{array}{c}\tau= \begin{cases}\tau_{\max }\left(\frac{s}{s_{0}}\right) & s \leq s_{0} \\
\tau_{\max }\left(\frac{s_{u l t}-s}{s_{u l t}-s_{0}}\right) & s>s_{0}\end{cases} \\
\tau_{\max }=1.8 k_{b} f_{t} \quad, \quad s_{0}=2.5 \tau_{\max }\left(n_{f} t_{f} / E_{f}+50 / E_{c}\right) \\
s_{u l t}=0.33 k_{b} \quad, \quad \beta_{w}=\sqrt{1.5 \times \frac{2-b_{f} / b_{c}}{1+b_{f} / 100}}\end{array}$ \\
\hline
\end{tabular}




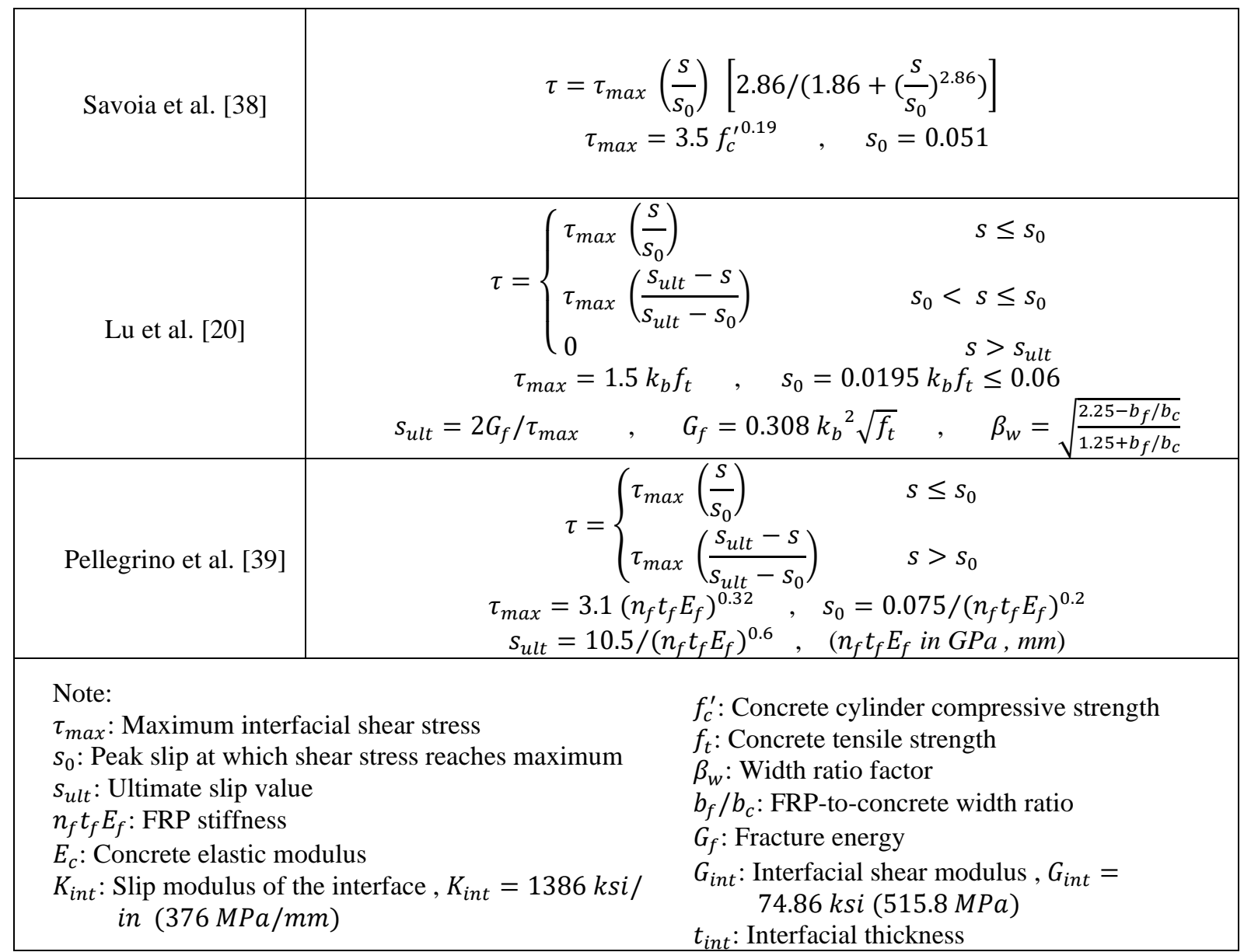

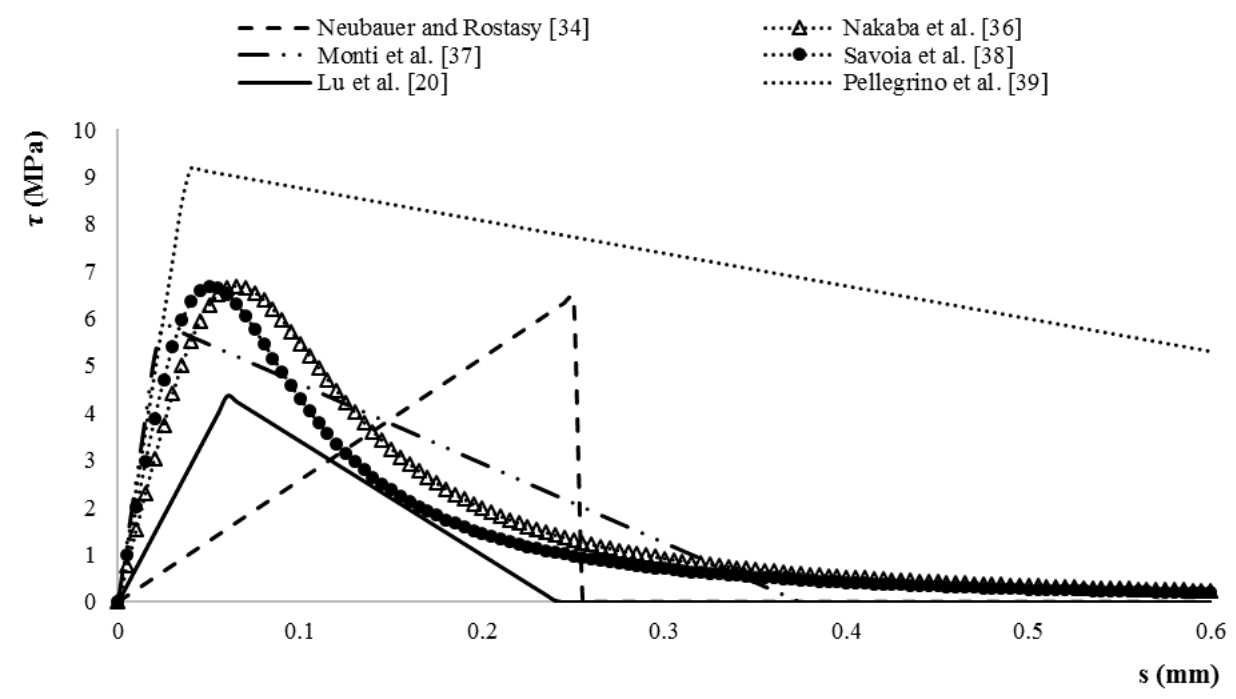

Fig. 2. Existing bond-slip models under static loading

Ko and Sato [24] developed a bond stress-slip model under cyclic loading based on Popovics [40] that agreed well with their own experimental results of double shear pull-out tests on 54 specimens. Indeed, two cyclic loading conditions (Cyclic 1 and 2) were considered in their experiments. During both cyclic loading conditions, a limited number of unload/reload paths were set. For Cyclic 1, the unloading loads corresponded to the maximum monotonic load capacity as well as the maximum monotonic displacement, whereas for Cyclic 2 condition, unloading of specimens was performed according to the maximum slips reached at each strain gauge location. Fig. 3 depicts the bond-stress curve of a tested specimen based on the envelopes derived from the cyclic hysteresis of the interfacial stress-slip relation. The proposed model, expressed in Eq. (1) and Eq. (2), involved several empirical 
parameters, including the maximum bond stress, $\tau_{\max }$, the corresponding slip, $s_{0}$, the curve characteristic constants, $c, c_{2}, c_{3}$, the unloading stiffness, $K_{u n}$, the ultimate slip, $s_{u l t}$, the friction stress, $\tau_{f p}$, the negative friction stress, $\tau_{f n}$ and the unloading slip $s_{u n}$ :

$$
\begin{gathered}
\tau=\frac{\frac{\tau_{\max \times} \times c \times s}{s_{0}}}{\left[(c+1)+\left(\frac{s}{s_{0}}\right)^{a}\right]} \\
K_{u n}=c_{2} \times s_{u n}{ }^{c_{3}}
\end{gathered}
$$

Where, $\tau$ and $s$ are the bond stress and slip of the FRP/concrete interface, respectively. Also, the constant values of $c, c_{2}, c_{3}$, and $a$ can be found from the experimental data in Ko and Sato [24]. Despite the fact that the results predicted by the model and the experimental data showed a good agreement, the proposed model was nevertheless developed on the basis of a limited number of loading/unloading repetitions. In addition, a linear approximation was adopted for the unload/reload path in the model for simplicity, which is inconsistent with the actual ovalshaped curves featured in the experiments [24].

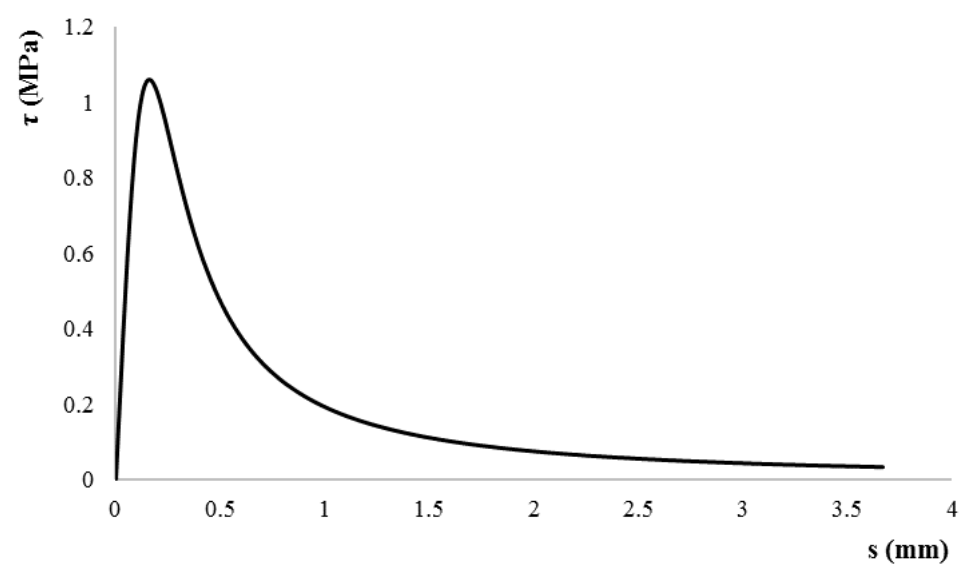

Fig. 3. Envelope-base bond-slip curve of a specimen tested by Ko and Sato [24] under cyclic loading

The following cyclic bilinear bond-slip model, as stated in Eqs. (3)-(7) and illustrated in Fig. 4, was proposed by Diab et al. [27] to characterize the fatigue behavior of the CFRP/concrete interface :

$$
\begin{gathered}
\tau=\left\{\begin{array}{lr}
\frac{\tau_{\text {max.t }}}{s_{0}} s & 0 \leq s \leq s_{0} \\
\frac{\tau_{\text {max.t }}}{s_{\text {ult. } .}-s_{0}}\left(s_{\text {ult.t }}-s\right) & s_{0}<s \leq s_{u l t . t}
\end{array}\right. \\
\tau_{\text {max.t }}=\frac{\tau_{\max .0}}{1+\varphi \cdot \alpha} \\
s_{\text {ult.t }}=\frac{\tau_{\max .0} \times s_{0}}{\tau_{\max . t}} \\
K_{b t}=\frac{K_{b 0}}{1+\varphi \cdot \alpha} \\
\varphi= \begin{cases}0.046(t)^{0.4} & t \leq 2000 \\
1.2(1-\exp (-t / 1200) & t>2000\end{cases}
\end{gathered}
$$

Where, $t$ is the cyclic loading time (in seconds), $\tau_{\max .0}$ and $\tau_{\text {max.t }}$ are the cyclic bond strengths of the adhesive at time zero and time $t$, respectively, $K_{b 0}$ and $K_{b t}$ are the cyclic stiffness values of the bond at time zero and time $t$, respectively, $s_{\text {ult.t }}$ is the cyclic ultimate slip (at time $t$ ), $\varphi$ is the creep fatigue coefficient, and $\alpha$ is a frequencydependent factor that is equal to 1 for a frequency of $5 \mathrm{~Hz}$. As can be seen, the cyclic dependent bilinear model successfully takes into account the degradation of interfacial stiffness under fatigue loading by adopting a simple creep-fatigue coefficient $(\varphi)$ in the equations. It should be noted that the model presented above was developed for the case of simple shear pull-out test. However, it has been argued that in actual debonding phenomenon, failure occurs due to the combined effects of shear and normal stresses near the cut-off points of bonded FRP [10]. 


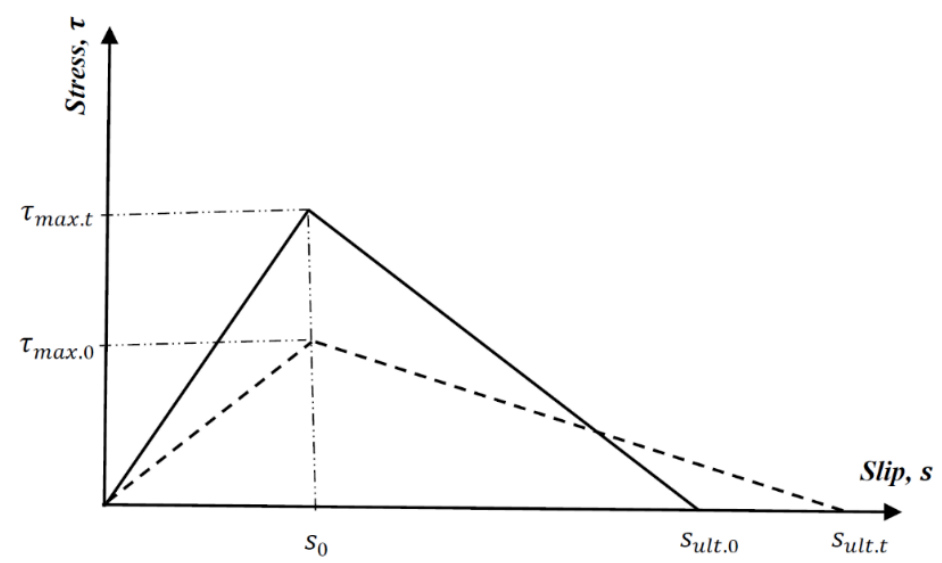

Fig. 4. Cyclic bilinear bond-slip model proposed by Diab et al. [27]

By examining the interfacial behavior of concrete and FRP in EB-FRP flexural strengthened RC beams under cyclic loading, Loo et al. [41] proposed a bond-slip model for concrete/FRP interaction. The proposed model, illustrated in Fig. 5, can be expressed by the following equations:

$$
\begin{aligned}
s_{b . \max } & =\frac{\tau_{b . \max }}{E_{b 0}}\left[1+K_{a} \times M(\log n)^{b} \times\left(\frac{\Delta \tau_{b}}{\tau_{b . u l t}}\right)^{h}\right] \\
E_{b} & =E_{b 0}\left[1+K_{2} \times \mu(\log n)^{\beta} \times\left(\frac{\Delta \tau_{b}}{\tau_{b . u l t}}\right)^{\lambda}\right]
\end{aligned}
$$

Where, $s_{b \text {.max }}$ is the slip (in mm) corresponding to the maximum applied average bond stress $\left(\tau_{b . \max }\right), \Delta \tau_{b}$ is the difference between the average bond stress at maximum cyclic load and the average stress at minimum load cycle, $\tau_{b \text {.ult }}$ is the average bond stress at the maximum load cycle, $N_{b}$, leading to bond failure (in $N / \mathrm{mm}^{2}$ ), $n$ is the number of load cycles, $E_{b}$ and $E_{b 0}$ are the moduli of elasticity of the bond (in $N / \mathrm{mm}^{2}$ ) at cycle $n$ and at the first loading cycle, respectively, and $K_{a}=K_{1} \log (n)$ and $K_{2}$ are factors defining the relationship between average bond stress and bonding length. By validating these equations with the limited literature data, the following parameters were determined: $=1.068, b=1.402, h=2.612, \mu=-190.3, \beta=0.990$ and $\lambda=8.797$. Based on numerical results, the proposed FE model showed good agreement with experimental results in terms of beam displacements at maximum loads, CFRP strains, and the number of load cycles to failure.

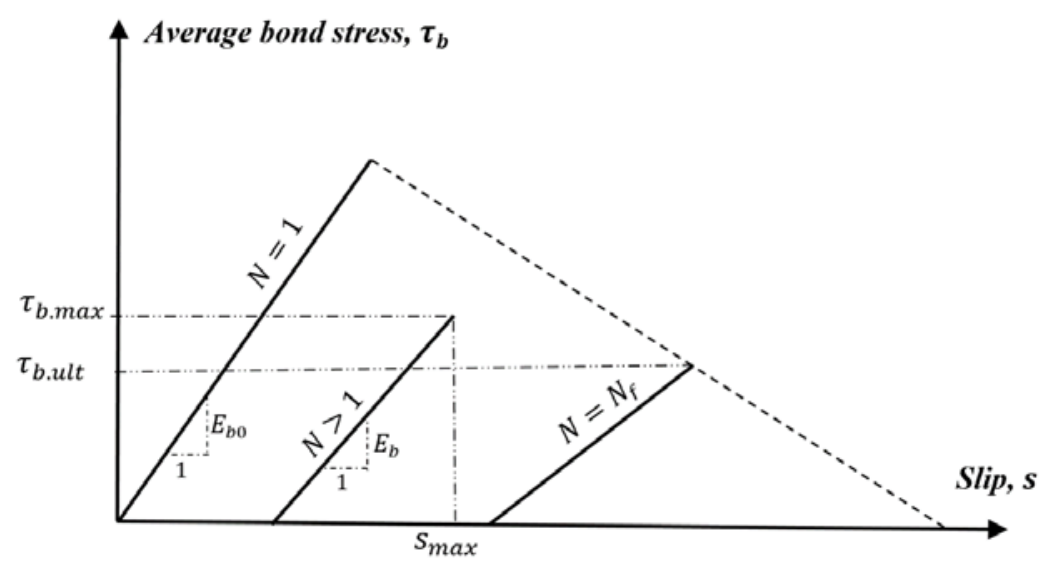

Fig. 5. Constitutive bond-slip model of Concrete/FRP interface under fatigue loading by Loo et al. [41]

Based on a regression analysis with limited experimental data, another bond stress-slip relationship was proposed by considering the effects of concrete strength and load amplitude under fatigue loading [30], as follows:

$$
\tau_{\text {max }}=\gamma \beta_{w}(1.085-0.648 T)\left(0.2233 f_{c u}-2.1433\right) e^{(38.46-112 T) \frac{n}{N}}
$$

Where, $\tau_{\max }$ is the maximum shear stress of the CFRP/concrete interface, $f_{c u}$ is the concrete cubic compressive strength, and $n$ and $N$ are the number of fatigue loading cycles and the fatigue life of specimens, respectively. $T$ is 
the ratio of the applied fatigue loading amplitude , $P_{\max }-P_{\min }$, to the monotonic capacity, $P_{u},\left(\frac{P_{\max }-P_{\min }}{P_{u}}\right)$ for each specimen, $\beta_{w}$ is the coefficient related to the ratio of the CFRP and concrete specimen's widths, $b_{f} / b_{c}$, and the coefficient $\gamma$ can be expressed as:

$$
\beta_{w}=\sqrt{\frac{2.25-b_{f} / b_{c}}{1.25+b_{f} / b_{c}}} \quad ; \quad \gamma=0.005 f_{c u}+0.7 \leq 1
$$

The proposed nonlinear bond-slip relationship successfully took into consideration the effect of fatigue degradation on the FRP/concrete bond behavior due to cyclic loading when calculating the maximum bond shear stress. However, in their experimental data analysis based on which the above-mentioned bond-slip model was developed, the effect of CFRP-to-concrete width ratio was not considered as a variable despite its demonstrated influence on the bond property of FRP/concrete interface as evidenced by reported experimental studies [31].

Also, an analytical study along with an experimental investigation by Li et al. [31] led to a bond-slip model for the concrete/FRP interface under cyclic loading, as expressed in Eqs. (12) - (20):

$$
\begin{gathered}
\tau=\left\{\begin{array}{cc}
\frac{\tau_{\text {max.t }}}{s_{0}} s & 0 \leq s \leq s_{0} \\
\frac{\tau_{\text {max.t. }}}{s_{\text {ult.t }}-s_{0}}\left(s_{\text {ult.t }}-s\right) & s_{0}<s \leq s_{u l t . t} \\
\tau=0 & s>s_{\text {ult.t }}
\end{array}\right. \\
s_{\text {ult.t }}=\frac{2 G_{f}}{\tau_{\max . t}} \\
G_{f}=\beta_{w}{ }^{2}\left(0.029 f_{c u}-0.2668\right) \\
\tau_{\max . t}=K_{t} s_{0} \\
K_{t}=\frac{K_{0}}{1+c_{k} \times n^{b_{k}}} \\
c_{k}=0.0007 \times e^{2.919 \times S_{c}{ }^{2}} \\
b_{k}=\left(0.873 \times S_{c}+0.0198\right)\left(1.208-0.00337 \times f_{c u}\right)\left(0.619 \times \frac{b_{f}}{b_{c}}+0.838\right) \\
S_{c}=\frac{T}{1-S_{a}} \\
S_{a}=\frac{P_{\max }+P_{\min }}{2 P_{u}}
\end{gathered}
$$

Where, $s_{0}$ and $s_{\text {ult.t }}$ are the slip corresponding to the maximum shear stress ( $\tau_{\text {max.t }}$ ) and the ultimate slip within the load cycles, respectively, $K_{0}$ and $K_{t}$ are the slopes of the ascending segment of the bond-slip curve at the initial load cycle and cycle $n$, respectively, $G_{f}$ is the interfacial fracture energy, $c_{k}, b_{k}$ are coeffcients obtained from the test results. $S_{c}$ is the cyclic load level, which is a function of the applied loading amplitude-to-ultimate load capacity ratio $(T)$ and the average cyclic loading-to-ultimate load capacity ratio $\left(S_{a}\right)$. It has been reported that the local slip at the maximum interfacial shear stress $\left(s_{0}\right)$ remains constant during the load cycles. However, the maximum cyclic shear stress $\left(\tau_{\text {max.t }}\right)$ and the maximum cyclic slip $\left(s_{u l t . t}\right)$ are both dependent on the number of load cycles, thereby keeping the interfacial fracture energy $\left(G_{f}\right)$ unchanged during cyclic loading. During the experimental testing, the performance of a series of specimens within four groups (A, B, C and D) was observed. The effects of loading amplitude and concrete strength were taken into consideration in group A and $\mathrm{B}$, whereas in groups $\mathrm{C}$ and $\mathrm{D}$, the bond length and FRP-to-concrete width ratio $\left(b_{f} / b_{c}\right)$ were chosen as the variables. Fig. 6 shows the bond-slip curves of a specimen (from group D) with respect to different number of load cycles, $n,(0$, 420, 2500 and 6500) obtained from the proposed model. It can be understood from the cyclic bond-slip curve that the slope of the ascending segment decreases as the number of cycles increases without causing a noticeable change in the amount of slip corresponding to the maximum bond shear stress $\left(s_{0}\right)$. The bond-slip curves derived from the two models developed by Zhu et al. [30] and Li et al. [31] are illustrated in Fig. 7 and Fig. 8 under different number of load cycles for specimens selected from group B and group C, with the following properties: $f_{c u}=35.3 \mathrm{MPa}$, $b_{f} / b_{c}=0.25 \mathrm{~mm}, \gamma=0.8765, T=0.5, N=88300$, for the specimen from group B and $f_{c u}=62.2 \mathrm{MPa}, b_{f} / b_{c}=$ $0.35 \mathrm{~mm}, \gamma=1, T=0.55, N=20680$, for the specimen from group C. As can be observed from the two figures, the results from both models tend to agree more with group-B specimens compared to group-C specimens. This is attributed to the fact that the parameter of FRP-to-concrete width ratio was considered in specimens from group B when developing the bond-slip model. Therefore, the superiority of the developed bond-slip model against the 
previous proposed models was that the effect of the CFRP-to-concrete width ratio was taken into account when deriving the bond-slip curves. In addition, the bilinear bond-slip model was reported to be simpler and more efficient for identifying the fatigue interfacial behavior of CFRP/concrete bond [31].

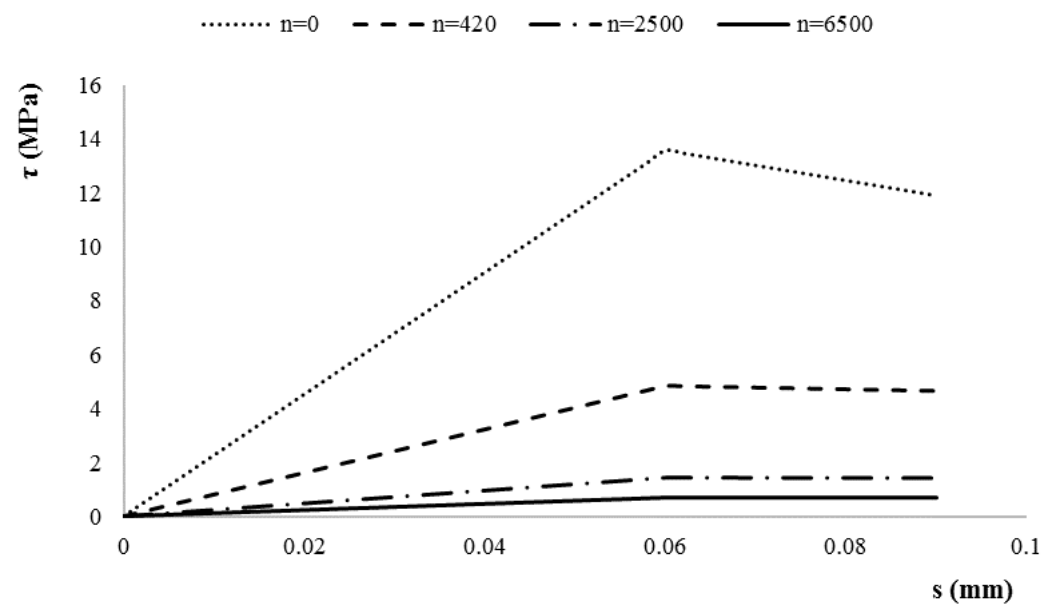

Fig. 6. Bond-slip curves of a tested specimen under different number of load cycles ( $n$ ) by Li et al. [31]

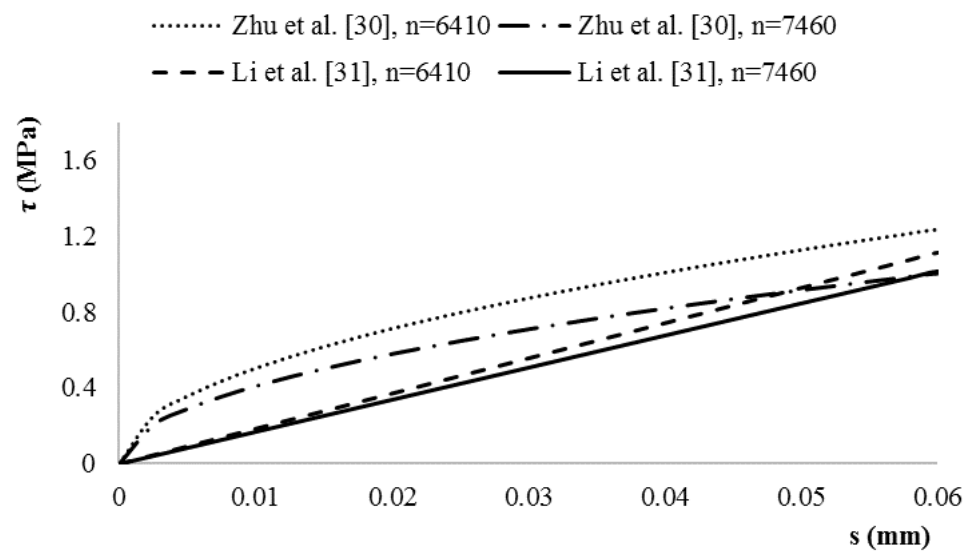

Fig. 7. Bond-slip model curves of a specimen from Group B (considering loading amplitude and concrete strength as variables)

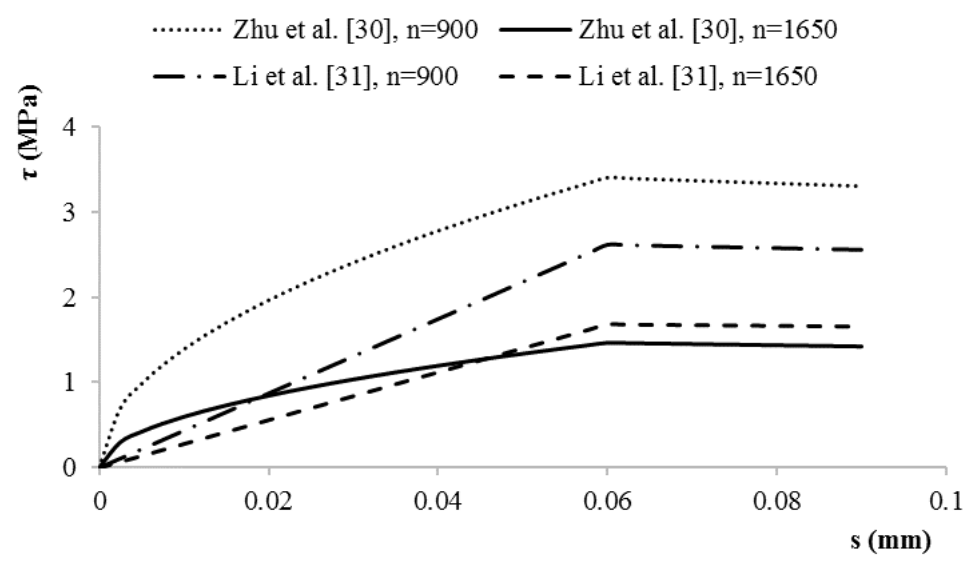

Fig. 8. Bond-slip model curves of a specimen from Group C (considering bond length and FRP-to-concrete width ratio as variables) 
Zhang [32] carried out some research to develop a bond stress-slip model and proposed the following equations to determine the local bond stress-slip relationship of specimens reinforced with high-strength (HS) CFRP plate. The proposed model, which was based on the model first presented by Popovics [40], showed good agreement with their own experimental results from a series of double-lap fatigue shear tests:

$$
\begin{gathered}
s_{e u}=0.046 \operatorname{EXP}(0.26 \log (n)) \\
\frac{K_{u n . i}}{K_{u n .1}}=1.25-0.20 \log (n) \\
\tau_{e u}=\tau_{\max } \frac{s_{e u}}{s_{0}} \times \frac{m}{(m-1)+\left(s_{e u} / s_{0}\right)^{m}}
\end{gathered}
$$

Where $s_{e u}$ and $\tau_{e u}$ are the slip and stress values on the envelope curve, respectively, $n$ is the number of fatigue cycles, $K_{u n . i}$ and $K_{u n .1}$ are the unloading stiffness at cycle $n$ and the unloading stiffness during the first cycle, respectively, which can be determined by the unloading slope from the envelope curve, $\tau_{\max }$ and $s_{0}$ are the maximum bond stress and the corresponding slip, respectively and $m$ is the curve characteristic constant which is equal to 3.44. The proposed model showed good agreement with the experimental results of specimens strengthened with HS CFRP plates. However, the applicability of the aforementioned model on other types of CFRP reinforcement requires further investigation.

Considering the cyclic bond-slip models discussed above, it is fair to say that the model developed by Li et al. [31], expressed in equations (12) - (20), has successfully taken into account the influencing factors, in particular FRP-to-concrete width ratio, and is able to predict interfacial shear stress of FRP-to-concrete bond under fatigue loading with adequate accuracy. Nevertheless, the proposed model was developed on the basis of limited experimental data and therefore its effectiveness can be enhanced by encompassing a wider range of test results.

\subsection{FRP/concrete bond fatigue life models}

A fatigue life model was proposed by Bizindavyi et al. [26] in the form of the following power-law relationship for FRP/concrete bonded members:

$$
S=\left(N_{b} \times C_{b}\right)^{-\omega}
$$

Where, $S$ is the cyclic mean bond stress range, and can be obtained from the maximum and minimum applied stresses, $S_{\max }-S_{\min }, N_{b}$ is the number of cycles to the bond failure, and $C_{b}$ and $\omega$ are constants obtained from test data. In their experimental investigation, which led to the aforementioned S-N model, two different FRP types, i.e., Glass FRP (GFRP) and Carbon FRP (CFRP), were applied to the specimens. It was observed from the S-N curves that the fatigue life of the FRP/concrete interface can be reduced by either increasing the applied stress level or decreasing the bond length.

Following an analytical investigation of the shear behavior of the FRP/concrete interface under fatigue loading, Diab et al. [27] proposed a prediction methodology to determine the fatigue life of the FRP/concrete interface. A nonlinear interfacial constitutive law was proposed to calculate the rate of debonding growth per loading cycle $\left(\frac{d a_{d}}{d n}\right)$, which can be expressed as follows:

$$
\frac{d a_{d}}{d n}=m_{1}\left(\frac{G_{\max }}{G_{c}}\right)^{n_{1}} \beta_{d}
$$

Where $a_{d}$ is the debonding length, $n$ is the number of cycles, $m_{1}$ and $n_{1}$ are parameters obtained from regression analysis of experimental tests, and $G_{\max }$ and $G_{c}$ are the maximum strain-energy release rate and the quasi-static fracture energy, respectively. Finally, $\beta_{d}$ is the fatigue debonding growth coefficient, which is used to account for the reduction in debonding propagation rate with increasing debonding length, $a_{d}$.

Li et al. [29] proposed a prediction model for the fatigue life of the FRP/concrete interface that takes into account the concrete cube compressive strength $\left(f_{c u}\right)$ and the CFRP-to-concrete width ratio $\left(b_{f} / b_{c}\right)$ as follows:

$$
\begin{aligned}
& \frac{S_{f}}{\left(1-S_{f . a}\right)}=1.90-0.0902\left\{\frac{0.0902 \ln N_{b}}{\left[\left(2.06 \times 10^{-3} f_{c u}\right)+0.872\right]\left[1.094-\left(0.382 b_{f} / b_{c}\right)\right.}\right\} \text { for } \\
& S_{f} /\left(1-S_{f . a}\right)>1.90-\left\{\frac{1.90-(0.3 / 0.7)}{\left[\left(2.06 \times 10^{-3} f_{c u}\right)+0.872\right]\left[1.094-\left(0.382 b_{f} / b_{c}\right)\right]}\right\} \\
& N_{b}>2 \text { million for } S /\left(1-S_{f . a}\right) \leq 1.90-\left\{\frac{1.90-(0.3 / 0.7)}{\left[\left(2.06 \times 10^{-3} f_{c u}\right)+0.872\right]\left[1.094-\left(0.382 b_{f} / b_{c}\right)\right]}\right\}
\end{aligned}
$$


In Eqs. (26) and (27), $N_{b}$ represents the fatigue life of the FRP/concrete interface, and $S_{f}$ and $S_{f . a}$ are the stress amplitude and related mean stress of the CFRP sheet at the mid-span of the four-point bending test, respectively and are given by:

$$
S_{f}=\frac{S_{f \cdot \max }-S_{f \cdot \min }}{S_{f . u}} \quad ; \quad S_{f . a}=\frac{S_{f \cdot \max }+S_{f \cdot \min }}{2 S_{f \cdot u}}
$$

Where $S_{f . u}=$ ultimate stress in the CFRP sheet at mid-span obtained from the monotonic test and $S_{f . \max }$ and $S_{f . m i n}$ are the maximum and minimum stress in the CFRP sheet at the mid-span (in the four-point bending test setup), obtained from the fatigue test, respectively. Hence, as can be understood from the prediction model, by measuring the applied stresses to CFRP and calculating the ratio $S /\left(1-S_{f . a}\right)$, the fatigue life of CFRP-to-concrete interface $\left(N_{b}\right)$ can be determined [29].

An S-N relationship of the CFRP/concrete bond was proposed by Zheng et al. [25] based on an experimental program including a series of double-lap shear tests on specimens with hygrothermal pre-treatment in which the temperature and relative humidity of environmental chambers were set according to the considerations stated in Zheng et al. [25]. It should be noted that by using Eq. (29), the CFRP/concrete bond fatigue strength $\left(S_{b}\right)$ was determined as $59 \%$ of static bond strength within 2 million load cycles $\left(N_{b}\right)$ :

$$
S_{b}=1.65-0.167 \log N_{b}
$$

In an experimental study by Xie et al. [33], the fatigue behavior of the interface between basalt-FRP (BFRP) sheets and concrete under marine environmental conditions (i.e., environment with large temperature variations and over repeated wet-dry cycles) was investigated. The following empirical equation was proposed to determine the fatigue life of the BFRP/concrete bond:

$$
S_{b}=1.16-0.088 \log N_{b}
$$

Where $S_{b}$ is the stress ratio of BFRP and $N_{b}$ is the number of cycles at which fatigue failure of the $\mathrm{BFRP} /$ concrete interface occurs. It is noteworthy that the measured fatigue strength of the BFRP/concrete interface with exposure to marine conditions was approximately $60 \%$ of its ultimate monotonic load-carrying capacity.

It can be understood from the S-N models discussed above that the interface between the FRP and concrete tends to comply with a different fatigue life relationship depending on various conditions, namely, Glass or Carbon FRP-to-concrete bond, bond in hygrothermal environment and also Basalt FRP-to-concrete interface. Hence, when applying the fatigue life model at the interface between FRP and concrete, it is of importance to ensure that the model corresponds to the right condition and predicts the fatigue behavior of the bond accordingly.

\subsection{Concrete compressive strength}

The influence of concrete compressive strength on the bond behavior of the FRP/concrete interface has been investigated through many experimental studies. Experimental investigations on the FRP-to-concrete bonded members have revealed different forms of debonding failure including concrete cover separation and intermediate crack-induced debonding [42]. In cases where the interfacial failure of the FRP/concrete bond is due to the concrete cover separation, it is reasonable to believe that increasing the concrete compressive strength could result in an enhancement in the ultimate load capacity of the bond between concrete and FRP under static loading [43]. Likewise, results of another investigation showed that increasing the concrete compressive contributes to reaching higher cohesive stress at the FRP/concrete interface as well as delaying the activation of FRP strain under static loading [44].

As far as fatigue loading is concerned, test observations have indicated that increasing the concrete strength extends the fatigue life of FRP/concrete interface [29, 30]. In an experimental study by Li et al. [29], specimens with three concrete cube compressive strengths of 62.2, 35.3, and 25.1 MPa bonded with CFRP were tested under the same fatigue loading ratio $\left(P_{\max } / P_{u}=0.65\right)$. It was shown that increasing the concrete strength from 25.1 MPa to 35.3 MPa and from 35.3 MPa to 62.2 MPa enhanced the number of load cycles to failure of CFRP/concrete interface by approximately $30 \%$ and $90 \%$, respectively. Similarly, it was reported by Chen and Cheng [45] that concrete with a higher compressive strength, and hence a higher tensile strength, could help hinder the fatigue crack propagation and lower the distributed axial strain on the FRP reinforcement, thereby improving the performance of the bond between FRP and concrete. An experimental program was carried out by Zhu et al. [30] on nine concrete beam specimens strengthened with EB-CFRP to study the bond-slip behavior of the CFRP/concrete interface under fatigue loading conditions for the same three concrete cube compressive strengths investigated by Li et al. [29] (i.e., 25.1 MPa, 35.3 MPa, and 62.2 MPa). It was observed that debonding may occur in one of the three regions of concrete cover, interface between concrete and epoxy, and interface between CFRP 
and epoxy. Furthermore, it has appeared that as concrete compressive strength increases, the fatigue life of the CFRP/concrete interface reaches higher levels, leading to an improvement in the performance of the bonding system. In addition, the maximum interfacial shear stress at the first cycle was seen to rise with an increase in the concrete strength. Indeed, an increase of about $40 \%$ and $230 \%$ in the shear stress of concrete/FRP interface was observed when the concrete strength increased from 25.1 MPa to 35.3 MPa and then from 35.3 MPa to 62.2 MPa, respectively. It may be of interest to note that higher concrete strength triggers the failure to occur as a result of CFRP sheet debonding from the epoxy resin rather than the concrete cover separation in the specimen [30]. Another study by Li et al. [31] showed that variations in the concrete compressive strength can affect the bondslip relationship of the FRP/concrete interface during the cyclic loading. Indeed, the slope of the ascending branch of the bond-slip curve tends to decrease at a lower rate during the load cycles, with an increase in the concrete strength.

\subsection{Bond length}

The effect of bond length on the fatigue behavior of the CFRP/concrete interface has been evaluated in many research studies. It was concluded in a research review that increasing FRP bond length enhances the fatigue life of the FRP/concrete interface [10]. In an experimental investigation by Li et al. [29], the fatigue endurance of the CFRP/concrete bond was evaluated with respect to bond lengths of 60, 160, and $240 \mathrm{~mm}$, where increased bond length contributed to higher bond fatigue endurance of the FRP/concrete interface. Indeed, test observations indicated that increasing the bond length from $60 \mathrm{~mm}$ to $160 \mathrm{~mm}$ resulted in an increase of about $338 \%$ in the fatigue life of CFRP/concrete interface, and when the bond length increased from $160 \mathrm{~mm}$ to $240 \mathrm{~mm}$, the number of cycles to failure of specimens has almost tripled. It was reported that, when the bond length increases, the increase in the fatigue life of the bond between CFRP and concrete was attributed to the fact that more loading cycles were needed to delaminate the CFRP sheets from the concrete [31]. Similar experimental results were observed in an study by Bizindavyi et al. [26], in which shorter bonded length seemed to reduce the fatigue life of the FRP/concrete interface by creating higher stress intensity levels at the FRP-to-concrete bond.

The effective bond length in FRP-strengthened concrete structures is defined as the minimum FRP bonded length at which the maximum force is transferred between the concrete substrate and the EB-FRP composite [23]. The effective bond length can be determined in experimental programs by taking the average of the bonded lengths of three specimens with the same load-carrying capacity at failure that have been tested constitutively, within a tolerance of $10 \%$ [46]. In the case of monotonic loading, the effective bond length $\left(l_{e}\right)$ can be obtained from the following equations according to existing guidelines:

$$
\begin{gathered}
l_{e}=\frac{23300}{\left(n_{f} \times E_{f} \times t_{f}\right)^{0.58}} \\
l_{e}=\frac{25350}{\left(n_{f} \times E_{f} \times t_{f}\right)^{0.58}} \\
l_{e}=\frac{\pi}{k_{b}} \sqrt{\frac{n_{f} \times E_{f} \times t_{f}}{8 f_{c m}^{2 / 3}}}, \quad k_{b}=\sqrt{\frac{2-b_{f} / b_{c}}{1+b_{f} / b_{c}}}
\end{gathered}
$$

Where, $n_{f}$ is the number of FRP layers, $E_{f}$ and $t_{f}$ are the elastic modulus and thickness of FRP, respectively, $f_{c m}$ is the concrete mean compressive strength and $b_{f} / b_{c}$ is the FRP-to-concrete width ratio.

It has been reported by $\mathrm{Li}$ et al. [29] that the effective bond length obtained experimentally under fatigue loading with the frequency of $2.5 \mathrm{~Hz}$ is less than that under monotonic loading at a rate of $0.001 \mathrm{~mm} / \mathrm{s}$. This can be attributed to the fact that the debonding failure of the specimen initiates at a lower load level during fatigue loading in comparison with that under quasi-static loading. Moreover, the interfacial crack propagation tends to occur in the epoxy adhesive rather than in the concrete under the fatigue condition [28, 29, 47]. It has also been experimentally observed that increasing the bond length beyond the effective bond length does not seem to affect either the debonding load level or the bond strength of the CFRP/concrete interface [29, 31].

\subsection{FRP-to-concrete width ratio}

As discussed in the bond-slip models, the factor of FRP-to-concrete width ratio $\left(b_{f} / b_{c}\right)$, included in some of the proposed bond slip models (see Eq. 11), plays a key role in determining the bond behavior of the FRP/concrete interface under fatigue loading; therefore, neglecting its effect could lower the accuracy of the bond-stress slip predictions obtained from the models. Considering the effect of FRP width on the fatigue behavior of the FRP/concrete interface, it has been experimentally observed that using narrower FRP laminates leads to higher slip values [26], which could be attributed to the greater stress concentration imposed on the FRP-to-concrete interface. Furthermore, a series of other experimental tests has revealed that the fatigue life of the FRP/concrete interface drops with increasing CFRP-to-concrete width ratio, which may be due to the fact that the interfacial 
bond capacity tends to increase at lower FRP-to-concrete ratios [29]. Another study by Li et al. [31] also showed that increasing the CFRP-to-concrete width ratio in strengthened concrete specimens during a sequence of load cycles reduces the fatigue resistance of the CFRP/concrete interface and accelerates the reduction in the slope of the ascending segment of the corresponding bond-slip curve.

\subsection{Fatigue loading amplitude}

Test results on the effect of fatigue loading amplitude revealed that the fatigue life of the CFRP/concrete interface tends to decline with increasing loading amplitude [25, 29, 33]. It has also been reported that at higher loads, the fatigue life of the concrete/FRP interface is dominated by crack initiation, whereas at lower fatigue load limits, crack propagation plays the main role in determining bond fatigue strength [28]. Experimental observations of cyclic single-lap shear tests conducted by Bizindavyi et al. [26] revealed that CFRP-strengthened concrete specimens are likely to fail due to rupture of laminates at higher applied cyclic stresses, particularly when the maximum stress is close to the static load-bearing strength of the CFRP laminate. This effect was also observed on the bond performance of near-surface mounted (NSM) strips under fatigue loading, where it has been demonstrated that the bond strength of NSM strips does not undergo a significant decrease provided that the upper applied load is less than $60 \%$ of the monotonic debonding load and that the stress amplitude of the FRP strip is kept below $250 \mathrm{MPa}$ [23]. Finally, an experimental study on the effect of fatigue loading amplitude by Zhu et al. [30] showed that an increase in the number of load cycles leads to a degradation of the bond stress-slip curve, meaning that shear stress is reduced under the same slip condition.

\section{Finite-element analysis of EB-FRP/concrete interface under fatigue loading}

Finite-element analysis (FEA) provides a cost-effective tool to evaluate structural behavior by taking into account a wide spectrum of influencing parameters without having to perform time-consuming and costly experiments [48]. Numerous studies have been carried out on the use of finite-element (FE) simulations of EBFRP strengthened RC structures and particularly of FE modeling of the FRP/concrete interface under both static and fatigue loading. It has been reported that applying an appropriate model for the FRP/concrete bond as well as the interface between the internal steel and concrete in FRP shear strengthened RC beams could significantly alter the numerical responses, in particular, the shear capacity of the beam under static loading [49]. However, Loo et al. [41] found that there is a negligible slippage between concrete and steel reinforcement in FRP strengthened RC structures during fatigue loading cycles. Hence, the FE modeling of steel/concrete interface does not affect the cyclic behavior of the structure as much as modeling of the bond between FRP and concrete. It should be noted that regarding numerical analysis of RC beams strengthened with EB-FRP under fatigue loading, researchers have investigated only the flexural behavior of structures, and to the authors' knowledge, there has been no investigation on FE modeling of the FRP/concrete interface in EB-FRP shear-strengthened RC beams under cyclic loading. Nevertheless, a few FE studies have been conducted on the fatigue behavior of the bond between concrete prisms and FRP materials in pull-out shear tests [50, 51].

\subsection{FE modeling of the FRP/concrete bond}

The modeling of the FRP/concrete interface has a significant effect on the numerical results derived from FE simulations. It is now well established that assuming a perfect bond between EB-FRP and concrete under monotonic loading results in over-estimation of the shear resistance of shear-strengthened RC beams [48, 49, 52]. The FE modeling of the interface between FRP and concrete under fatigue loading has been performed in a few studies, which led to an enhancement in the numerical results validated with the experimental observations. In a numerical investigation on the fatigue performance of EB-FRP strengthened RC beams in flexure by Wang et al. [53], the concrete/FRP bond behavior was defined using the bilinear bond-slip model proposed by Lu et al. [20]. As for the bond geometry modeling, contact elements (TARGE170 and CONTA174) in ANSYS were used. The contact elements were able to take into account the shear stresses between the two interfacial surfaces by applying a Coulomb friction model. Also, in FE simulations performed by Pathak and Zhang [54] on EB-FRP strengthened RC beams in flexure under cyclic loading, the model developed by Loo et al. [41] was adopted to characterize the bond-slip behavior of the interface between FRP and concrete. Spring elements in ANSYS were used to simulate the interfaces between concrete, adhesive and FRP. This two-node nonlinear element has no physical mass and dimension and can incorporate the cyclic bond-slip model for the interfacial behavior. Indeed, through the implementation of the cyclic bond-slip models in the FEA of FRP-strengthened RC structures, a more accurate prediction of the bond behavior was achieved.

In another study, the EB-CFRP/concrete interface was simulated based on the Mohr-Coulomb criterion with tension cut-off [55]. Accordingly, the linear relationship between the interfacial stresses and the corresponding displacements in the tangential and normal directions $\left(\Delta v_{1} \cdot \Delta v_{2} \cdot \Delta u\right)$ was expressed according to the following equation: 


$$
\left\{\begin{array}{c}
\tau_{1} \\
\tau_{2} \\
\sigma
\end{array}\right\}=\left[\begin{array}{ccc}
k_{t t} & 0 & 0 \\
0 & k_{t t} & 0 \\
0 & 0 & k_{n n}
\end{array}\right]\left\{\begin{array}{l}
\Delta v_{1} \\
\Delta v_{2} \\
\Delta u
\end{array}\right\}
$$

Where $\tau$ and $\sigma$ are the shear and normal stresses, respectively and $k_{t t}$ and $k_{n n}$ are the initial elastic normal and shear stiffnesses, respectively. The numerical model successfully evaluated the fatigue life of RC beams with different levels of flexural deficiencies when compared to the corresponding experimental data.

Fatigue modeling of the EB-FRP/concrete interaction has also been investigated in numerical studies of shear pull-out tests. Daud et al. [50] performed a numerical analysis on a single shear pull-out test and evaluated the interfacial behavior between the concrete block and the bonded CFRP plate under post-fatigue loading condition. The bond between the concrete and the EB-CFRP was represented using cohesive elements in which a traction separation model was applied. In another numerical investigation simulating a series of single shear pull-out tests of CFRP bonded concrete blocks under fatigue loading [51], the interaction between the concrete and the CFRP laminate was modeled using two techniques. In the first technique, a solid element with a perfect bond was used to represent the adhesive between the concrete and the CFRP, whereas in the second, an interface element was assumed between the two components. It was concluded that using a solid element with a perfect bond exhibited more realistic specimen behavior under fatigue loading than using an interface element.

\subsection{Numerical parametric studies on the FRP/concrete bond}

Numerical investigations have been conducted to evaluate the influence of different parameters on the behavior of bond between FRP and concrete, specially in FRP strengthened RC beams, under both monotonic and fatigue loading. In a numerical study by Al-Rousan and Issa [56] under fatigue loading, the effects of applied stress range, CFRP-to-concrete contact area, and number of CFRP layers on the flexural capacity and deflection of the strengthened beam were assessed. The applied load range corresponded to various ratios of steel yielding stress $\left(f_{s . y}\right)$, including $0.25 f_{s . y}-0.35 f_{s . y}, 0.45 f_{s . y}-0.65 f_{s . y}, 0.65 f_{s . y}-0.90 f_{s . y}$, and $0.45 f_{s . y}-0.90 f_{s . y}$. The stress range had a considerable influence on the structural behavior in terms of mid-span deflection, stiffness degradation, and failure mode, particularly for the fatigue stress range of $0.45 f_{s . y}-0.90 f_{s . y}$. Further numerical results proved that increasing either the CFRP contact area with concrete or the number of CFRP layers leads to an enhancement in stiffness and ultimate load capacity, as well as a reduction in mid-span beam deflection. Likewise, through nonlinear FEA of CFRP-strengthened RC beams in flexure under cyclic loading, Pathak and Zhang [54] indicated that increasing the FRP thickness resulted in a decrease in beam deflection as well as FRP strain. However, in a numerical parametric study of the number of CFRP layers on the fatigue life of FRP strengthened RC beams by Banjara and Ramanjaneyulu [55], it was shown that using three CFRP layers did not significantly increase the load-carrying capacity of beams over that achieved with two layers of CFRP.

According to the numerical results, it was also observed that carbon FRP (CFRP) strips exhibited a better performance in reducing beam deflection and increasing beam fatigue life when compared to glass FRP (GFRP) strips. Furthermore, the computational results demonstrated that beams strengthened with longer FRP sheets underwent less central deflection and showed lower FRP strain [54].

The effect of prestressing CFRP on the fatigue behavior of flexural strengthened RC beams was analyzed in a FE study by Guo et al. [57]. Various prestressing levels ( $0 \%, 10 \%, 15 \%$, and $22 \%$ ) were modelled by applying initial stress values to the CFRP laminates. Increasing the prestressing level resulted in enhanced beam fatigue life by reducing the stresses on the reinforcing bars. However, using prestressed laminates tended to increase damage to the CFRP/concrete interface, increasing thereby the possibility of debonding failure. Similar conclusions were made by Wang et al. [58] upon FEA of RC beams strengthened in flexure with prestressed hybrid FRP (HFRP), consisting of hybrid carbon and glass FRP (C/GFRP), under fatigue loading. It was stated that applying too much prestressing could lead to a large reversed arch and premature fracture of C/GFRP composites.

Environmental conditions can also affect the fatigue behavior of FRP-strengthened beams in flexure. Indeed, numerical observations have shown that hygrothermal conditions (high temperature, high humidity) can decrease the strength of the CFRP/concrete interface and increase the stress level of internal steel reinforcement, in turn leading to an accelerated rate of damage at the CFRP/concrete interface and at the main longitudinal steel reinforcement under fatigue loading [59]. It has also been observed that CFRP-strengthened beams in an indoor environment tend to fail as a result of steel reinforcing rupture under fatigue loading, whereas the failure mode of beams in hygrothermal environments was found to be debonding of the CFRP/concrete interface [59].

An assessment of the effect of various design parameters such as concrete compressive strength, CFRP stiffness, CFRP-to-concrete width ratio, and CFRP bond length on the post-fatigue performance of the CFRP/concrete interface was conducted in a numerical investigation consisting of a single pull-out test [50]. The study revealed that increasing the bond length increases the ultimate load capacity until the effective bond length is provided, after which the ultimate load tends to stabilize. As for variation in concrete compressive strength, higher concrete 
strength results in an increase in bond strength, provided that the failure mode is concrete surface separation (delamination) beneath the adhesive layer. However, specimens that failed because of CFRP rupture did not seem to be affected by the change in concrete strength. Finally, numerical observations indicated that an increase in the CFRP-to-concrete width ratio results in an increase in CFRP bond strength, which agreed with the corresponding experimental results.

Based on reported numerical results from FRP/concrete pull-out tests, it was also stated that shear-strengthened structures with EB-CFRP laminates are able to perform better in terms of fatigue resistance, provided that the maximum applied stress is less than $75 \%$ of the ultimate monotonic load capacity [51].

\section{Synthesis and discussion}

Research studies of FRP/concrete interaction show that the debonding in EB-FRP strengthened concrete blocks mainly occur in the form of concrete surface separation. Hence, the FRP/concrete bond behavior is greatly affected by concrete compressive strength. Indeed, increasing the concrete compressive strength is likely to enhance the interfacial fatigue life as well as the bond strength. Similarly, bond length has been reported to affect the FRP/concrete interface. However, CFRP/concrete bond strength does not seem to be affected by increasing the CFRP bond length beyond the effective bond length derived from fatigue experimental tests. In contrast, by considering the effect of fatigue loading range, an inverse relationship between the applied load amplitude and the fatigue life of the FRP/concrete bond was revealed, meaning the FRP-to-concrete interface tends to fail at lower load cycles when subjected to higher amplitudes of fatigue loading. Furthermore, based on reported experimental results, increasing the number of load cycles results in reduced maximum shear stress of the FRP/concrete interface. However, that does not seem to affect the maximum apparent slip at the FRP/concrete interface.

Looking into the proposed bond-slip models under fatigue loading, it can be understood that a reliable model needs to take into account all the influencing parameters, including concrete compressive strength, bond length, FRP-to-concrete width ratio and fatigue loading amplitude. It can also be seen from the fatigue bond-slip models that the maximum interfacial shear stress tends to decrease with an increase in the number of load cycles. Furthermore, comparison between the proposed bond-slip models shows that when the FRP-to-concrete ratio is not considered as a factor affecting the fatigue behavior of FRP/concrete interface, the bond-slip model is not likely to provide accurate predictions of the bond behavior under fatigue loading. However, discrepancies between the few existing models may suggest the need for more investigations in this respect.

Available experimental studies of FRP/concrete bond behavior under fatigue loading revealed that the influence of concrete tensile strength has yet to be examined. Since the effect of concrete tensile strength on bond behavior at the FRP/concrete interface is significant, an investigation of fatigue bond behavior with respect to concrete tensile strength seems to be necessary.

Based on reported numerical investigations, it could be concluded that FE analysis of EB-FRP strengthened RC structures is a reliable tool for predicting structural responses as well as evaluating influencing parameters under both monotonic and fatigue loading. A review of related research studies indicates that the accuracy of FE models of EB-FRP shear-strengthened RC beams depends greatly on the performance of the concrete/FRP interface model. Indeed, assuming a perfect bond at the FRP/concrete interface will lead to over-estimated structural predictions in terms of bond strength and load-carrying capacity. Hence, the FRP/concrete bond can contribute to highly realistic prediction of structural capacity when simulated by appropriate bond-stress slip models. Furthermore, numerical parametric studies under cyclic loading have indicated that the fatigue life of the FRP/concrete interface depends on a number of factors. These influencing parameters include applied load range, FRP-to-concrete width ratio, FRP bonded length, FRP thickness, FRP type and also environmental conditions. According to the observations from FRP bonded concrete pull-out tests, concrete compressive strength, FRP-toconcrete width ratio and FRP bond length (lower than the effective bond length) have significant influence on the bond strength between concrete and FRP, especially when the failure mode is concrete surface separation. Furthermore, by setting the applied stress level to its endurance limit (75\% of the ultimate capacity), the long term fatigue resistance of EB-FRP shear strengthened RC beams can be reached.

\section{Research needs}

Based on this review of research studies on the FRP/concrete bond behavior of EB-FRP shear-strengthened RC structures under fatigue loading, the following research gaps and needs were identified:

1) Since available studies regarding the fatigue life of the bond between FRP and concrete have been conducted based on limited data, more research studies are required to develop reliable S-N relationships corresponding to the fatigue life of the EB-FRP/concrete interface, especially in FRP shear-strengthened RC structures, by incorporating all the influencing factors.

2) Special attention must be devoted to the fatigue bond behavior of the FRP/concrete interface in shear- 
strengthened RC structures, and reliable bond stress-slip models should be proposed that fully capture the influencing parameters, especially under fatigue conditions similar to real-life situations.

3) Numerical investigations must be conducted to evaluate the performance of shear-strengthened RC structures with respect to the FRP/concrete bond under fatigue loading by considering various influencing factors, including concrete compressive strength, bond length, FRP ratio, and environmental conditions.

4) Research should be undertaken to evaluate the effect of environmental conditions as well as moisture on the fatigue performance of the FRP/concrete interface in FRP shear-strengthened RC beams.

5) Because concrete tensile strength is a key parameter affecting the interfacial behavior between concrete and FRP materials under fatigue loading, more research is required to evaluate its effect on FRP-strengthened RC beams, particularly in shear.

\section{Conclusions}

A state of knowledge has been presented with a focus on the fatigue behavior of the FRP/concrete bond in EBFRP strengthened RC structures in shear, and a wide spectrum of related aspects were covered. These include the influencing parameters under cyclic loading, existing design guidelines, prior investigations of fatigue bond behavior at the FRP/concrete interface, and numerical analyses of the FRP/concrete bond in EB-FRP strengthened RC structures under fatigue loading. Based on the reported literature, the following conclusions can be drawn:

1) CFRP composites have enhanced fatigue properties that can be used to increase the fatigue life of RC beams.

2) The bond at the CFRP/concrete interface is influenced by numerous variables under fatigue loading, including concrete strength, fatigue load amplitude, CFRP-to-concrete width ratio, and bond length.

3) Increasing the concrete compressive strength improves the bond behavior under fatigue loading by increasing the fatigue life of the interface. For instance, an increase of about $75 \%$ in the concrete strength enhanced the fatigue life of the bond by around $90 \%$, as reported in the literature.

4) Increasing the bond length can result in an increase in the fatigue life of the FRP/concrete interface. For instance, increasing the bond length by around $166 \%$ led to an increase of approximately $338 \%$ in the fatigue life of the bond, according to the reported experimental data.

5) A hygrothermal environment (high temperature and high humidity) can have an adverse influence on the fatigue life of the CFRP/concrete bond in EB-FRP strengthened beams in flexure.

6) For all developed fatigue bond-slip models, the slope of the ascending section tends to decrease with increasing number of load cycles. Increasing the concrete compressive strength also decreases the rate of slope reduction of the ascending branch. In contrast, an increase in either the level of fatigue loading or the CFRP-toconcrete width ratio increases the rate of slope reduction.

7) Finite-element analysis (FEA) of EB-FRP strengthened RC structures under fatigue loading, when validated with literature data, is a reliable and cost-effective alternative to experimental investigation for evaluating the influencing parameters on structural performance.

8) The accuracy of FEA of EB-FRP strengthened RC beams relies on accurate concrete/FRP interface modeling.

9) Assuming a perfect bond between concrete and FRP leads to over-estimation of the predicted shear resistance. Using proper bond-slip models along with interfacial elements to simulate the FRP/concrete interface will enhance the accuracy of shear capacity predictions with respect to experimental data.

10) Based on numerical simulations, the fatigue behavior of the EB-FRP/concrete bond can be affected by design parameters as well as environmental conditions.

\section{Acknowledgements}

We would like to acknowledge the Natural Sciences and Engineering Research Council of Canada (NSERC) and the Fonds de Recherche du Québec - Nature et Technologie (FRQNT) for their financial support through operating grants.

\section{References}

[1] Chaallal O, Boussaha F, Bousselham A. Fatigue performance of RC beams strengthened in shear with CFRP fabrics. Journal of Composites for Construction. 2010;14:415-423.

[2] El-Saikaly G, Chaallal O. Extending the fatigue life of reinforced concrete T-beams strengthened in shear with externally bonded FRP: Upgrading versus repairing. Journal of Composites for Construction. 2015;19:04014027.

[3] Azim MR, Gül M. Damage detection of steel girder railway bridges utilizing operational vibration response. Structural Control and Health Monitoring. 2019;26:e2447.

[4] FHWA. Federal Highway Administration (FHWA), Highway bridges by state and highway system, USA. 
2017.

[5] Kim YJ, Heffernan PJ. Fatigue behavior of externally strengthened concrete beams with fiber-reinforced polymers: state of the art. Journal of Composites for Construction. 2008;12:246-256.

[6] Aidoo J, Harries KA, Petrou MF. Fatigue behavior of carbon fiber reinforced polymer-strengthened reinforced concrete bridge girders. Journal of Composites for Construction. 2004;8:501-509.

[7] Oudah F, El-Hacha R. Research progress on the fatigue performance of RC beams strengthened in flexure using Fiber Reinforced Polymers. Composites Part B: Engineering. 2013;47:82-95.

[8] El-Saikaly G, Chaallal O. Extending the fatigue life of reinforced concrete T-beams strengthened in shear with externally bonded FRP: Upgrading versus repairing. Journal of Composites for Construction. 2015;19:04014027.

[9] ACI-215R. Considerations for design of concrete structures subjected to fatigue loading: American Concrete Institute, Farmington Hills, Michigan; 1974.

[10] Wu Z, Kim YJ, Diab H, Wang X. Recent developments in long-term performance of FRP composites and FRP-concrete interface. Advances in Structural Engineering. 2010;13:891-903.

[11] ACI-440.2R. American Concrete Institute, ACI Committee 440, Guide for the design and construction of externally bonded FRP systems for strengthening concrete structures. Farmington Hills, Michigan: American Concrete Institute; 2017.

[12] Barnes RA, Mays GC. Fatigue performance of concrete beams strengthened with CFRP plates. Journal of composites for construction. 1999;3:63-72.

[13] Brena SF, Benouaich MA, Kreger ME, Wood SL. Fatigue tests of reinforced concrete beams strengthened using carbon fiber-reinforced polymer composites. ACI structural journal. 2005;102:305.

[14] Heffernan P, Erki M. Fatigue behavior of reinforced concrete beams strengthened with carbon fiber reinforced plastic laminates. Journal of Composites for Construction. 2004;8:132-140.

[15] Masoud S, Soudki K, Topper T. CFRP-strengthened and corroded RC beams under monotonic and fatigue loads. Journal of composites for construction. 2001;5:228-236.

[16] Toutanji H, Zhao L, Deng Y, Zhang Y, Balaguru P. Cyclic behavior of RC beams strengthened with carbon fiber sheets bonded by inorganic matrix. Journal of Materials in Civil Engineering. 2006;18:28-35.

[17] Harries K. Fatigue behaviour of bonded FRP used for flexural retrofit. Proceedings of international symposium on bond behaviour of FRP in structures (BBFS 2005): International Institute for FRP in Construction Hong Kong, China; 2005. p. 547-552.

[18] Diab H, Wu Z. Review of existing fatigue results of beams externally strengthened with FRP laminates. Proceedings of the 4th International Conference on FRP Composites in Civil Engineering (CICE2008). 2008.

[19] Danraka MN, Mahmod HM, Oluwatosin O-kJ, Student P. Strengthening of Reinforced Concrete Beams using FRP Technique: A Review. International Journal of Engineering Science. 2017;7:13199.

[20] Lu X, Teng J, Ye L, Jiang J. Bond-slip models for FRP sheets/plates bonded to concrete. Engineering structures. 2005;27:920-937.

[21] Zhou H, Fernando D, Dai J-G. The bond behaviour of CFRP-to-concrete bonded joints under fatigue cyclic loading: An experimental study. Construction and Building Materials. 2021;273:121674.

[22] CSA-S6. CSA S6:19, Canadian highway bridge design code. 12th edition. ed. Toronto, Ontario, Canada: CSA Group; 2019.

[23] fib-TG5.1. Externally applied FRP reinforcement for concrete structures: International Federation for Structural Concrete, Bulletin 90, Task group 5.1, Lausanne, Switzerland; 2019.

[24] Ko H, Sato Y. Bond stress-slip relationship between FRP sheet and concrete under cyclic load. Journal of Composites for Construction. 2007;11:419-426.

[25] Zheng X, Huang P, Chen G, Tan X. Fatigue behavior of FRP-concrete bond under hygrothermal environment. Construction and Building Materials. 2015;95:898-909.

[26] Bizindavyi L, Neale K, Erki M. Experimental investigation of bonded fiber reinforced polymer-concrete joints under cyclic loading. Journal of Composites for Construction. 2003;7:127-134.

[27] Diab H, Wu Z, Iwashita K. Theoretical solution for fatigue debonding growth and fatigue life prediction of FRP-concrete interfaces. Advances in structural engineering. 2009;12:781-792.

[28] Carloni C, Subramaniam KV, Savoia M, Mazzotti C. Experimental determination of FRP-concrete cohesive interface properties under fatigue loading. Composite Structures. 2012;94:1288-1296.

[29] Li K, Cao S-Y, Wang X-L. Experimental Study on the Fatigue Endurance of the CFRP-Concrete Interface. Journal of Composites for Construction. 2015;19:04014075.

[30] Zhu J-T, Wang X-L, Kang X-D, Li K. Analysis of interfacial bonding characteristics of CFRP-concrete under fatigue loading. Construction and Building Materials. 2016;126:823-833.

[31] Li K, Cao S, Yang Y, Zhu J. Bond-Slip Relationship for CFRP Sheets Externally Bonded to Concrete under Cyclic Loading. Materials. 2018;11:336.

[32] Zhang W. Prediction of the Bond-Slip Law Between Externally Bonded Concrete Substrates and CFRP Plates 
Under Fatigue Loading. International Journal of Civil Engineering. 2018;16:1085-1096.

[33] Xie J-H, Wei M-W, Huang P-Y, Zhang H, Chen P-S. Fatigue behavior of the basalt fiber-reinforced polymer/concrete interface under wet-dry cycling in a marine environment. Construction and Building Materials. 2019;228:117065.

[34] Neubauer U, Rostasy F. Bond failure of concrete fiber reinforced polymer plates at inclined cracksexperiments and fracture mechanics model. Special publication. 1999;188:369-382.

[35] De Lorenzis L, Miller B, Nanni A. Bond of FRP laminates to concrete. ACI materials journal. 2001;98:256264.

[36] Nakaba K, Kanakubo T, Furuta T, Yoshizawa H. Bond behavior between fiber-reinforced polymer laminates and concrete. Structural Journal. 2001;98:359-367.

[37] Monti G, Renzelli M, Luciani P. FRP adhesion in uncracked and cracked concrete zones. Fibre-Reinforced Polymer Reinforcement for Concrete Structures: (In 2 Volumes): World Scientific; 2003. p. 183-192.

[38] Savoia M, Ferracuti B, Mazzotti C. Non linear bond-slip law for FRP-concrete interface. Fibre-Reinforced Polymer Reinforcement for Concrete Structures: (In 2 Volumes): World Scientific; 2003. p. 163-172.

[39] Pellegrino C, Tinazzi D, Modena C. Experimental study on bond behavior between concrete and FRP reinforcement. Journal of Composites for Construction. 2008;12:180-189.

[40] Popovics S. A numerical approach to the complete stress-strain curve of concrete. Cement and concrete research. 1973;3:583-599.

[41] Loo KYM, Foster SJ, Smith ST. FE modeling of CFRP-repaired RC beams subjected to fatigue loading. Journal of Composites for Construction. 2012;16:572-580.

[42] Chen C, Li X, Wang X, Sui L, Xing F, Li D, et al. Effect of transverse groove on bond behavior of FRPconcrete interface: Experimental study, image analysis and design. Composites Part B: Engineering. 2019;161:205-219.

[43] Abdalla JA, Mirghani A, Hawileh RA. Bond stress and behavior of interface between untreated aluminum alloy surface and concrete. Procedia Structural Integrity. 2020;28:1295-1302.

[44] Chen C, Cheng L. Single Crack-Based Model for FRP Shear-Strengthened RC Beams. Journal of Composites for Construction. 2019;23:04019030.

[45] Chen C, Cheng L. Predicting flexural fatigue performance of RC beams strengthened with externally bonded FRP due to FRP debonding. Journal of Bridge Engineering. 2017;22:04017082.

[46] CSA-S806. S806-12 Design and construction of building structures with fibre-reinforced polymers: Ontario: Canadian Standards Association; 2012.

[47] Carloni C, Subramaniam KV. Investigation of sub-critical fatigue crack growth in FRP/concrete cohesive interface using digital image analysis. Composites Part B: Engineering. 2013;51:35-43.

[48] ACI-447.1R. Report on the modeling techniques used in finite element simulations of concrete structures strengthened using fiber-reinforced polymer materials: American Concrete Institute, Farmington Hills, Michigan; 2018.

[49] Chen G, Chen J, Teng J. On the finite element modelling of RC beams shear-strengthened with FRP. Construction and Building Materials. 2012;32:13-26.

[50] Daud RA, Cunningham LS, Wang YC. New model for post-fatigue behaviour of CFRP to concrete bond interface in single shear. Composite Structures. 2017;163:63-76.

[51] Al-Saoudi A, Al-Mahaidi R, Kalfat R, Cervenka J. Finite element investigation of the fatigue performance of FRP laminates bonded to concrete. Composite Structures. 2019;208:322-337.

[52] Godat A, Neale KW, Labossière P. Numerical modeling of FRP shear-strengthened reinforced concrete beams. Journal of Composites for Construction. 2007;11:640-649.

[53] Wang X, Sayed Ahmed M, Wu Z. Modeling of the Flexural Fatigue Capacity of RC Beams Strengthened with FRP Sheets Based on Finite-Element Simulation. Journal of Structural Engineering. 2014;141:04014189.

[54] Pathak P, Zhang YX. Numerical study of structural behavior of fiber-reinforced polymer-strengthened reinforced concrete beams with bond-slip effect under cyclic loading. Structural Concrete. 2019;20:97-107.

[55] Banjara NK, Ramanjaneyulu K. Investigations on behaviour of flexural deficient and CFRP strengthened reinforced concrete beams under static and fatigue loading. Construction and Building Materials. 2019;201:746-762.

[56] Al-Rousan R, Issa M. Fatigue performance of reinforced concrete beams strengthened with CFRP sheets. Construction and Building Materials. 2011;25:3520-3529.

[57] Guo X, Wang Y, Huang P, Chen Z. Finite element modeling for fatigue life prediction of RC beam strengthened with prestressed CFRP based on failure modes. Composite Structures. 2019;226:111289.

[58] Wang X, Zhou C, Ai J, Petrů M, Liu Y. Numerical investigation for the fatigue performance of reinforced concrete beams strengthened with external prestressed HFRP sheet. Construction and Building Materials. 2020;237:117601. 
[59] Wang Y, Guo X, Huang P, Huang K, Yang Y, Chen Z. Finite element investigation of fatigue performance of CFRP-strengthened beams in hygrothermal environments. Composite Structures. 2020;234:111676.

(C) 2021 by the author(s). This work is licensed under a Creative Commons Attribution 4.0 International License (http://creativecommons.org/licenses/by/4.0/). Authors retain copyright of their work, with first publication rights granted to Tech Reviews Ltd. 